UNIVERSIDADE MANDUME YA NDEMUFAYO INSTITUTO SUPERIOR POLITÉCNICO DA HUÍLA

DEPARTMENT OF INFORMATIC AND SYSTMS

AHP METHODS

Alberto Raimundo Wapota (betoray@yahoo.com.br) PhD

Abel Zacariasn(abel.zacarias@yahoo.com.br) MSc

Joseph Rafael (josephlubango@gmail.com) Esudent 


\section{SIMULATION OF AHP METHOD}

It is intended to equip the ISPH the Computing Laboratory. To this end, three competing suppliers of computer equipment, among them the NCR, SISTEC, CINFOTEC and Office-One. It is known however that only a supplier can be selected, taking the criteria: price, quality and strength-equipment. As for the price, the amount charged by equipping for each supplier company is: NCR $=\$$ $9,000.00$, SISTEC $=\$ 10,500.00, \$ 10,000.00$ and CINFOTEC $=$ Office-One $=\$$ $8,000.00$.

Step 1: we need to structure the problem in the form of diagram, where we started to represent the overall objective of the organization (ISPH) consisting of select supplier taking into account the criteria price, quality and product resistance as follows:

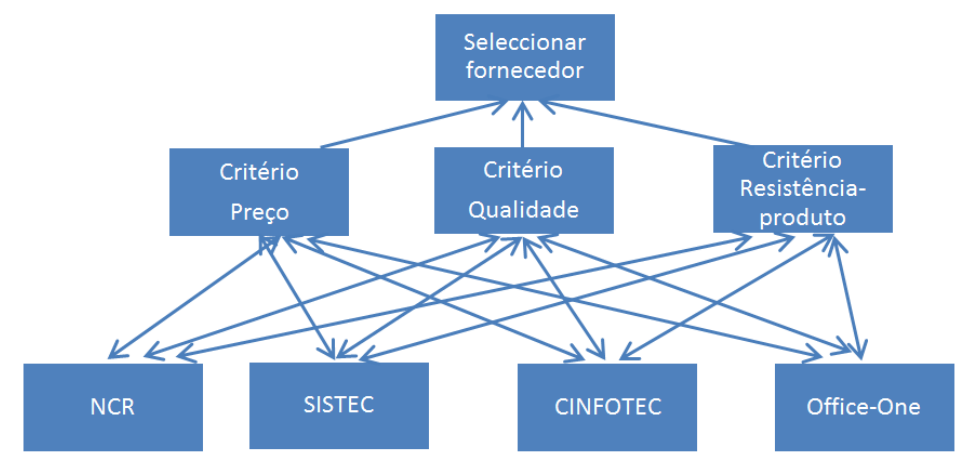

Step 2: is to develop the first table that the criteria of judgment matrix, ie assign the importance of each criterion on the other criteria, then determine the geometric mean of each criterion and then the normalized vector, based on the SCALE FUNDAMENTAL (T. Saaty):

\begin{tabular}{|l|c|c|c|c|c|}
\hline Ilmportance & iqual & moderate & Strong & Muito Forte & Exactilly Strong \\
\hline Numerical Rep & 1 & 3 & 5 & 7 & 9 \\
\hline
\end{tabular}

Where the numbers 2, 4, 6 e 8 are intermadiate values.

For example you can judge the quality criterion has a strong importance on the price criteria and moderate on the Resist-Equip criteria as the first table attached resolution. 
Note: This judgment is made by the organization, ie, it is up to the organization to decide which of the criteria think is most important in the selection of alternatives (suppliers).

Step 3: is to determine the weight of the alternatives (NCR, SISTEC, CINFOTEC and Office-One) depending on the price criterion, namely to know which alternative is best when referring to the price and determine the normalized vector of each alternative, and consider the following:

1- As prices have already been taken by suppliers (alternatives), we no longer make the judgment, only we determine the normalized vector of each alternative in terms of price;

2 Given that the organization (ISPH) the price is a criterion such as "The less better and the more worse," before determining the normalized vector have to harmonize, as shown in resolução-

Step 4: is to develop the third table that is the judgment matrix of alternatives depending on quality criteria, ie to know which alternative is best when referring to quality, based on the FUNDAMENTAL SCALE (T. Saaty) in then determining the geometric mean of each alternative and then the normalized vector.

Step 5: is to develop the fourth table that the judgment matrix of alternatives depending on the Resist-Equip criterion, namely to know which alternative is best when we refer to resistance of the equipment, based on the FUNDAMENTAL SCALE (T. Saaty) and then determine the geometric mean of each alternative and then the normalized vector.

Step 6: is to develop the fifth table that lists the alternatives for each criterion that is that to illustrate the weight of the alternatives in each of the criteria. Then we determine the sum-product between the rows that contain the weights of each alternative (determined in steps 3, 4 and 5) and the line containing the normalized vectors of criteria (determined in Step 2). The result of the sumproduct is the Vector Decision. 
Conclusion: According to the resolution, ie taking into account the judgments made has as the best alternative for the equipping of ISPH the Computer Laboratory, the CINFOTEC supplier (see resolution). 